\title{
Single Low-Dose Methotrexate-Induced Fatal Pancytopenia: Case Report and Review of the Literature
}

\author{
Burak Uz* \\ Adult Hematology Clinic, Medicana International Samsun Hospital, Turkey
}

*Corresponding author: Burak Uz, Yenimahalle Mahallesi, Şehit Mesut Birinci Caddesi, No: 85, 55080, Canik/Samsun, Turkey

ARTICLE INFO
Received: 畔 February 26, 2019
Published: March 12, 2019
Citation: Burak Uz. Single Low-Dose
Methotrexate-Induced Fatal Pancyto-
penia: Case Report and Review of the
Literature. Biomed J Sci \& Tech Res
15(5)-2019. BJSTR. MS.ID.002763.

15(5)-2019. BJSTR. MS ID.002763.

Abbreviations: RA: Rheumatoid Arthritis; CT: Computed Tomography; ANC: Absolute Neutrophil Count

\begin{abstract}
Methotrexate (MTX) is a disease-modifying anti-rheumatic drug which has a worlwide use due to its efficacy and safe therapeutic window. MTX-induced pancytopenia has been reported to be in $1.0-1.4 \%$ of rheumatoid arthritis patients treated with MTX. Although this complication usually occurs in a dose-dependent manner, it may also occur via an idiosyncratic reaction which is usually unpredictable and potentially fatal. A 63-year-old woman presented with oral mucositis and fever. Her initial laboratory examinations revealed pancytopenia and acute renal dysfunction. She had a history of new-onset ( 2 weeks before) polymyalgia rheumatica for which she was under $10 \mathrm{mg}$ MTX weekly treatment. After only single dose of peroral MTX (10 mg), the patient developed grade 4 neutropenia and thrombocytopenia, and grade 2 anemia. Filgrastim, leucovorin, broad-spectrum antibiotics, multiple blood components, and urine alcalinization were administered. The neutropenia recovered on day 28 of MTX administration. However, despite all supportive medical care efforts including vasopressors, the patient expired on day 40 from respiratory failure due to septic shock. It should be kept in mind that low-dose MTX administration may lead to deep pancytopenia and eventually death. Oral mucositis and fever may herald hematologic toxicity in such cases. Immediate withdrawn of MTX and intensive supportive measures are warranted.
\end{abstract}

\section{Introduction}

Methotrexate (MTX) is a disease-modifying anti-rheumatic and anti-folate drug which inhibits dihydrofolic acid reductase. Lowdose MTX regimen (5 - $25 \mathrm{mg}$ / week) has gained wide acceptance due to its safe therapeutic window in a variety of rheumatologic diseases including rheumatoid arthritis (RA), systemic lupus erythematosus, psoriasis, and so on. MTX can develop toxicity on tissues especially with high proliferative capacity (e.g. mucosal layers, gastrointestinal tract and bone marrow) even in low doses due to its intracellular accumulation in polyglutameted form [1]. The prevalance of MTX-induced hematological toxicity and pancytopenia in patients treated with RA is estimated to be $3 \%$ [2-4] and 1.0-1.4\% [3,5], respectively. MTX-induced pancytopenia is usually dose-dependent [6], but occasionally it may occur by an idiosyncratic reaction $[3,4]$. However, the prevalance and the exact mechanism of idiosyncratic pancytopenia induced by MTX is unkown. We report a case of pancytopenia, neutropenic fever and transient acute renal insufficiency which proved to be fatal after administration of a single-dose $(10 \mathrm{mg}$ ) of peroral MTX.

\section{Case Presentation}

\section{Admission and Inpatient Period}

A 63-year old woman admitted to emergency servise with lassitude, oral mucositis, odynohagia, and lack of appetite which limited her oral intake for nearly ten days. The patient was in reduced general condition. Her past history was significant for hypertension (known for approximately 30 years), coronary artery disease, arrhythmia, congestive heart failure, and type 2 diabetes mellitus (known for approximately 9 years). Her medications included ramipril, amlodipin, valsartan, hydrochlorothiazide, dabigatran, bisoprolol, furosemid, and metformin. Two weeks before presentation, she was diagnosed with polymyalgia rheumatica and MTX $10 \mathrm{mg} / \mathrm{wk}$, folic acid $10 \mathrm{mg} / \mathrm{wk}$, and dexamethasone $7.5 \mathrm{mg} /$ 
day was prescribed (Table 1). Vital signs disclosed the following: temperature $36.0 \mathrm{C}$, blood pressure $100 / 70 \mathrm{~mm} \mathrm{Hg}$, and heart rate $101 \mathrm{bpm}$. Physical examination revealed lack of skin turgor and oral

Table 1: The clinical parameters of the patient.

\begin{tabular}{|c|c|}
\hline Parameters & Patient \\
\hline Age / sex & $63 / F$ \\
\hline MTX dose (week) & $10 \mathrm{mg}$ \\
\hline MTX duration & 1 week \\
\hline Cumulative dose & $10 \mathrm{mg}$ \\
\hline Onset of pancytopenia & 13 days after MTX administration \\
\hline Nadir of blood counts & ANC: $0 \times 10^{3} \mathrm{u} / \mathrm{L}$ on day $13^{*} ; \mathrm{Hb} ; 6.5 \mathrm{~g} / \mathrm{dl}$ on day $19^{*} ;$ PLT: $7 \times 10^{3} \mathrm{u} / \mathrm{L}$ on day $18^{*}$ \\
\hline Clinical presentation & fever, oral mucositis, reduced general condition \\
\hline Folate dose (week) & $10 \mathrm{mg}$ \\
\hline Concomitant diseases & HT, DM, CAD, CHF, arrhythmia, depression \\
\hline Concomitant drugs & dexamethasone (7.5 mg/day) \\
\hline Treatment for pancytopenia & folinic acid rescue, G-CSF, antibiotics \\
\hline Outcome & recovery from neutropenia on day $28^{*}$, died on day $40^{*}$ \\
\hline Number of packed RBC given & 6 \\
\hline Number of pooled platelet suspension given & 9 \\
\hline Number of fresh frozen plasma given & 4 \\
\hline
\end{tabular}

Abbreviations: F: female; MTX: methotrexate; ANC: absolute neutrophil count; Hb: hemoglobin; PLT: platelet; HT: hypertension; DM: diabetes mellitus; CAD: coronary artery disease; CHF: congenital heart failure; G-CSF: granulocyte-colony stimulating factor; RBC: red blood cell

*days are counted from the administration of MTX

Table 2: The initial and follow-up laboratory parameters of the patient is depicted below. She was taken into Intensive Care Unit (Isolation Room) on day 11 of her hospital stay.

\begin{tabular}{|c|c|c|c|c|c|c|}
\hline Parameters & On Admission & 1. Week & 2. Week & 3. Week & 4. Week & Reference Range \\
\hline WBC $\left(\mathrm{x} 10^{3} \mathrm{u} / \mathrm{L}\right)$ & 0.61 & 0.68 & 1.51 & 14.08 & 25.39 & $4-10$ \\
\hline ANC $\left(\mathrm{x} 10^{3} \mathrm{u} / \mathrm{L}\right)$ & 0.05 & 0 & 0.85 & 12.39 & 23.34 & $2-8$ \\
\hline Hemoglobin (g/dl) & 9.7 & 7.6 & 7.2 & 7.6 & 6.9 & $12-15.1$ \\
\hline MCV (fL) & 68.5 & 68.7 & 75.9 & 80 & 83.9 & $80-96$ \\
\hline Platelets (x10 $\mathrm{u} / \mathrm{L})$ & 62 & 19 & 10 & 29 & 175 & $150-450$ \\
\hline Serum creatinine (mg/dl) & 2.39 & 0.71 & 0.96 & 0.79 & 1.52 & $0.5-1.2$ \\
\hline Serum albumin (g/dl) & 4 & NA & 2.3 & 3 & 2.7 & $3.4-5.4$ \\
\hline AST / ALT (U/l) & $27 / 17$ & $40 / 71$ & $22 / 13$ & $274 / 72$ & $121 / 51$ & $(0-37) /(0-50)$ \\
\hline CRP (mg/dL) & 55.82 & 31.7 & 23.2 & 30.26 & 31.97 & $0-0.5$ \\
\hline Procalcitonine (ng/ml) & NA & NA & 0.926 & 0.921 & 2.71 & $0-0.5$ \\
\hline
\end{tabular}

Abbreviations: WBC: white blood cell; ANC: absolute neutrophil count; MCV: mean cell volume; NA: not available; AST: aspartate aminotransferase; ALT: alanine aminotransferase; CRP: C-reactive protein

Because her complete blood count and renal function tests done 7 weeks prior to the present admission were normal (except a moderate anemia which was attributed to chronic disease anemia), a possible diagnosis of MTX-induced pancytopenia was suspected. She was subsequently administered filgrastim (480 $\mu$ g twice a mucositis. The initial laboratory data showed pancytopenia, acute deterioration in renal function tests, and a high C-reactive protein level (Table 2). Serum MTX level was $0.20 \mu \mathrm{mol} / \mathrm{L}$ 
2 and 6, the patient had recurrent gastrointestinal system bleeding. Despite close monitoring and blood component replacements (Table 1), her lower gastrointestinal bleeding did not stop, and she had recurrent neutropenic fever. Endoscopic examinations could not have been performed due to grade 4 neutropenia and neutropenic fever. On day 7 , serum MTX level decreased to $<0.04$ $\mu \mathrm{mol} / \mathrm{L}$. Consequently, folinic acid rescue was withdrawn.

\section{Intensive Care Unit}

On day 11, the patient was taken into intensive care unit (isolation room) because of hemodynamic instability and reduced general condition. On day 13, the patient had recurrent neutropenic fever. Prior blood culture revealed positivity for Pseudomonas aeruginosa and her antibiotherapy was scrutinized accordingly (including moxifloxacin and meropenem). On day 15, the patient started to have abundant productive and bloody respiratory secretions. A thorax computed tomography (CT) revealed bilateral pleural effusion, alveolonodular opacities, and ground-glass densities in lower lobes (predominantly in left lobe) which were suggestive of an infective process. Additionally, the patient's neutropenia recovered for the first time at day 15 [white blood cell (WBC): $2.88 \times 10^{\wedge} 3 \mathrm{u} / \mathrm{L}$, absolute neutrophil count (ANC): 2.09 $\left.\mathrm{x} 10^{\wedge} 3 \mathrm{u} / \mathrm{L}\right]$. Her lower GIS bleeding stopped on day 17.

\section{Entubation Period and Exitus}

On day 19 , she had to be entubated because of a respiratory arrest followed by a cardiac arrest. On day 22, a control thorax CT revealed significant increase in bilateral ground-glass densities. A tracheal aspirate culture was found to be positive for Klebsiella pneumonia. Therefore, her antibiotherapy was then switched to imipenem and colistin. On day 27, she became increasingly hypotensive and tacchycardic due to septic shock requiring dopamine and norepinephrine. Despite close monitoring and intensive supportive measures, she expired on day 27 of hospital stay (40 days after administration of MTX) due to uncontrolled pulmonary enfection and septic shock.

\section{Discussion}

MTX-induced pancytopenia have rarely been reported with low cumulative doses ( $<25 \mathrm{mg}$ ). To the best of our knowledge, a total of 5 cases were reported (Table 3) $[3,4,7,8]$. The minimal cumulative MTX dose leading to fatal pancytopenia was $10 \mathrm{mg}$ (as was in our patient) who had dialysis-free renal impairment and hypoalbuminemia. The mortality rate, including our own, was $67 \%$. These cases may represent an idiosyncratic/type B reaction (immunological or hypersensitive phenomenon) of MTX which is unpredictable and potentially fatal. Mori et al. have retrospectively analyzed 40 patients who were treated with a relative low-dose MTX (mean cumulative dose: $254 \mathrm{mg}$ ) and concluded that myelosupression can develop abruptly at any time during treatment. MTX-related severe neutropenia (ANC <500/ $\mathrm{mm}^{\wedge} 3$ ) was significantly more often detected within the first two months of MTX treatment. Mortality rate was $10 \%$ and all fatal cases were seen in the severe neutropenic group. Unexpectedly, disease severity was not-dependent on MTX doses [9]. Similarly, in the Scandinavian Study, all the patients treated with low-dose MTX developed pancytopenia abruptly [4].

Table 3: The clinical data and outcome of patients who were treated with low cumulative dose $(\leq 25 \mathrm{mg})$ methotrexate.

\begin{tabular}{|c|c|c|c|c|c|c|c|c|}
\hline Case & Reference & Age/Sex & $\begin{array}{c}\text { MTX } \\
\text { Dosage }\end{array}$ & $\begin{array}{c}\text { Duration of MTX Treat- } \\
\text { ment }\end{array}$ & $\begin{array}{l}\text { Cumulative } \\
\text { Dose (mg) }\end{array}$ & Risk Factors & $\begin{array}{l}\text { Concurrent } \\
\text { Drugs }\end{array}$ & Outcome \\
\hline 1 & Omdal et al. & $60 / F$ & $\begin{array}{c}7.5 \mathrm{mg} / \\
\mathrm{wk}\end{array}$ & 2 weeks & 15 & $\begin{array}{l}\text { renal impairment, amyloi- } \\
\text { dosis, hypoalbuminemia }\end{array}$ & $\begin{array}{c}\text { polipharmacy } \\
(>5)\end{array}$ & Exitus \\
\hline 2 & $\begin{array}{l}\text { Gutierrez-U- } \\
\text { reña et al. }\end{array}$ & $63 / F$ & $5 \mathrm{mg} / \mathrm{wk}$ & 2 weeks & 10 & $\begin{array}{l}\text { renal impairment, hypoal- } \\
\text { buminemia, infection }\end{array}$ & $\begin{array}{l}\text { NSAIDs, aceta- } \\
\text { minophen }\end{array}$ & Exitus \\
\hline 3 & $\begin{array}{l}\text { Kuitunen } \\
\text { et al. }\end{array}$ & NA & $\begin{array}{c}5 \text { and } 7.5 \\
\mathrm{mg} / \mathrm{wk}\end{array}$ & 2 weeks & 12.5 & NA & NA & NA \\
\hline 4 & $\begin{array}{l}\text { Kuitunen } \\
\text { et al. }\end{array}$ & NA & $\begin{array}{l}7.5 \mathrm{mg} / \\
\mathrm{wk}\end{array}$ & 2 weeks & 15 & NA & NA & NA \\
\hline
\end{tabular}




\begin{tabular}{|c|c|c|c|c|c|c|c|c|}
\hline 5 & $\begin{array}{l}\text { Preet Singh } \\
\text { et al. }\end{array}$ & $50 / \mathrm{F}$ & $\begin{array}{l}5 \mathrm{mg} / \\
\text { day* }\end{array}$ & 5 days* & 25 & $\begin{array}{l}\text { MTX overdose, lack of } \\
\text { folate supplemantation, } \\
\text { sepsis }\end{array}$ & $\begin{array}{l}\text { prednisolone, } \\
\text { NSAIDs }\end{array}$ & Exitus \\
\hline 6 & Present case & $63 / F$ & $10 \mathrm{mg} / \mathrm{wk}$ & 1 week & 10 & $\begin{array}{l}\text { renal impairment, polip- } \\
\text { harmacy }\end{array}$ & $\begin{array}{l}\text { polipharmacy } \\
(>5)^{* *}\end{array}$ & Exitus \\
\hline
\end{tabular}

Abbreviations: MTX: methotrexate; F: female; wk: week; NSAIDs: nonsteroidal anti-inflammatory drugs; NA: not available.

*Overdose due to prescription error

**Ramipril, amlodipin, valsartan, hydrochlorothiazide, dabigatran, bisoprolol, furosemid, and metformin

American College of Rheumatology recommends complete blood count, serum creatinine, and transaminases to be performed at baseline, 2-4 weekly for the first 3 months, 8-12 weekly for the next 3 months, and 12 weekly thereafter [10]. MTX-induced pancytopenia is potentially fatal. The mortality rate varied from 17 to $44 \%$ as per severity of pancytopenia $[3,4,6,9,11]$. Recently, WBC at admission was found to be a predictor of survival in a series of 46 patients with MTX-induced pancytopenia. Of the patients who had an initial WBC of $<1000 / \mathrm{mm}^{3}$, only one third of them survived. Moreover, ANC was significantly higher (1297 vs $516 / \mathrm{mm}^{3}$ ) in patients who survived than those who expired. Potential predisposing risk factors were as follows: hypoalbuminemia (50\%), renal insufficiency (30.4\%), prescribing errors (28.3\%), and lack of folate supplementation (15.2\%) [12]. Other risk factors for MTX-induced pancytopenia are advanced age, usage of anti-folate drugs or polipharmacy ( $>5$ drugs), concomitant infection, and a prior history or documentation of MTX-induced pancytopenia [3,12]. In addition, some polymorphisms (C677T and 1298AA) are associated with a susceptibility to cytopenia $[13,14]$. In the present case, a relatively advanced age and polypharmacy were present. Her serum transaminase as well as albümin levels were in normal ranges.

Although her prior renal function tests were normal, she presented with acute renal deterioration (Table 2). A 9-year history of type $2 \mathrm{DM}$, dehydration as a result of preceding oral mucositis and odynophagia, and administration of MTX itself could have been the potential causes of acute renal insufficiency. Time to recovery of cytopenia is also a critic issue for the patients suffered from MTX-induced severe pancytopenia. The median time needed for recovery is $4-6$ days $[7,12]$. Needless to say, prolonged recovery time is associated with severe infections and sepsis. Ajmani et al. have reported that most common cause of death was sepsis. The most common affected site was pulmonary tract which was followed by urinary and gastrointestinal tracts [3,12]. Similary, the infection site was pulmonary area in the present patient. However, the recovery time from neutropenia was 15 days which was longer than expected (Table 1 and 2). This report highlights the need of close hematologic monitorization during low-dose MTX treatment. Single-dose MTX administration (even with 10 $\mathrm{mg}$ ) can cause severe pancytopenia followed by neutropenic fever. Oral mucositis and fever can herald deep pancytopenia which can lead to severe mortality and morbidity. In the presence of these findings close laboratory monitoring is mandatory, since MTXinduced pancytopenia can occur abruptly at any given time during treatment.

\section{References}

1. Shiver MB, Hall LA, Conner KB, Brown GE, Cheung WL, et al. (2014) Cutaneous erosions: a herald for impending pancytopenia in methotrexate toxicity. Dermatol Online J 20(7): 13030.

2. Mc Kendry RJ (1997) The remarkable spectrum of methotrexate toxicities. Rheum Dis Clin North Am 23(4): 939-954.

3. Gutierrez Ureña S, Molina JF, García CO, Cuéllar ML, Espinoza LR (1996) Pancytopenia secondary to methotrexate therapy in rheumatoid arthritis. Arthritis Rheum 39: 272-276.

4. Kuitunen T, Malmström J, Palva E, Pettersson T (2005) Pancytopenia induced by low-dose methotrexate. A study of the cases reported to the Finnish Adverse Drug Reaction Register From 1991 to 1999. Scand J Rheumatol 34(3): 238-241.

5. Salliot C, Van Der Heijde D (2009) Long-term safety of methotrexate monotherapy in patients with rheumatoid arthritis: a systematic literature research. Ann Rheum Dis 68(7): 1100-1104.

6. Lim AY, Gaffney K, Scott DG (2005) Methotrexate-induced pancytopenia: serious and under-reported? Our experience of 25 cases in 5 years. Rheumatology (Oxford) 44(8): 1051-1055.

7. Omdal R, Gøransson L, Bergrem H (1993) Fatal outcome of low-dose methotrexate therapy in rheumatoid arthritis. Clin Rheumatol 12: 283284.

8. Preet Singh Y, Aggarwal A, Misra R, Agarwal V (2007) Low-dose methotrexate-induced pancytopenia. Clin Rheumatol 26(1): 84-87.

9. Mori S, Hidaka M, Kawakita T, Hidaka T, Tsuda H, et al. (2016) Factors Associated with Myelosuppression Related to Low-Dose Methotrexate Therapy for Inflammatory Rheumatic Diseases. PLoS One 11(4): e0154744.

10. Saag KG, Teng GG, Patkar NM, Anuntiyo J, Finney C, et al. (2008) American College of Rheumatology 2008 recommendations for the use 
of nonbiologic and biologic disease-modifying antirheumatic drugs in rheumatoid arthritis. Arthritis Rheum 59(6): 762-784.

11. Mameli A, Barcellona D, Marongiu F (2017) Fatal Cytopenia Induced by Low-Dose Methotrexate in Elderly With Rheumatoid Arthritis. Identification of Risk Factors. Am J Ther 24(1): e106-e107.

12. Ajmani S, Preet Singh Y, Prasad S, Chowdhury A, Aggarwal A, et al. (2017) Methotrexate-induced pancytopenia: a case series of 46 patients. Int J Rheum Dis 20: 846-851.

\section{ISSN: 2574-1241}

DOI: 10.26717/BJSTR.2019.15.002763

Burak Uz. Biomed J Sci \& Tech Res

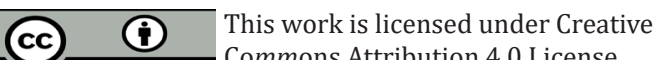

Submission Link: https://biomedres.us/submit-manuscript.php
13. Ulrich CM, Yasui Y, Storb R, Schubert MM, Wagner JL, et al. (2001) Pharmacogenetics of methotrexate: toxicity among marrow transplantation patients varies with the methylenetetrahydrofolate reductase C677T polymorphism. Blood 98: 231-234.

14. Berkun Y, Levartovsky D, Rubinow A, Orbach H, Aamar S, et al. (2004) Methotrexate related adverse effects in patients with rheumatoid arthritis are associated with the A1298C polymorphism of the MTHFR gene. Ann Rheum Dis 63(10): 1227-1231.

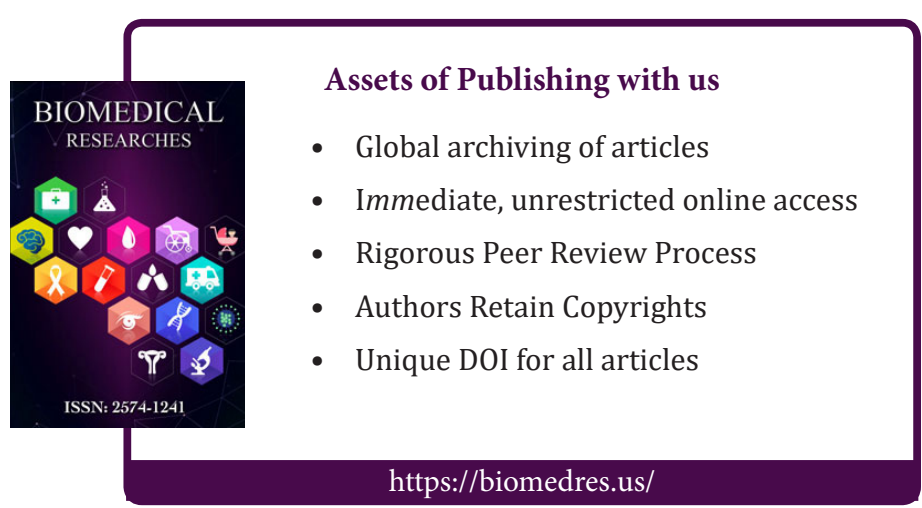

